\title{
Synthesis of 1
}

To a deprotonated stirred solution of pyridine-2,5-dicarboxylic acid (167 mg, 1.0 mmol) and $\mathrm{KOH} 1.0 \mathrm{M}(3.5 \mathrm{mmol})$ in $\mathrm{H}_{2} \mathrm{O}\left(2.5 \mathrm{~cm}^{3}\right)$ was added a solution of cobalt(II) chloride hexahydrate $(356 \mathrm{mg}, 1.5 \mathrm{mmol})$ in $\mathrm{H}_{2} \mathrm{O}\left(4.0 \mathrm{~cm}^{3}\right)$ to give a Co:L:OH ratio of 3:2:7. The combined reactants were heated to $230{ }^{\circ} \mathrm{C}$ over $24 \mathrm{~h}$ and then cooled at a rate of $0.10^{\circ} \mathrm{C} \mathrm{min}{ }^{-1}$ to room temp to give purple needles of 1 which were decanted several times with portions of $\mathrm{H}_{2} \mathrm{O}$ and cleaned further under an optical microscope (yield $155 \mathrm{mg}, 54 \%$ ). Anal. Found: C, 28.8; H, 2.0; N, $4.8 \%$; $\mathrm{C}_{14} \mathrm{H}_{12} \mathrm{Co}_{3} \mathrm{~N}_{2} \mathrm{O}_{12}$ requires: $\mathrm{C}, 29.1 ; \mathrm{H}, 2.1 ; \mathrm{N}, 4.9 \%$. $\lambda_{\max }$ (powder/nm): $781.6(0.300)$, 578.4 (0.618), 476.0 (0.562), 277.5 (0.768). $v_{\max }\left(\mathrm{KBr} / \mathrm{cm}^{-1}\right): 3452.8 \mathrm{~m}, 3358.5 \mathrm{br} \mathrm{m}$, 3226.4 br m, $3119.9 \mathrm{~m}, 1653.7 \mathrm{~s}, 1620.2 \mathrm{~s}, 1482.3 \mathrm{w}, 1430.3 \mathrm{~m}, 1409.7 \mathrm{~m}, 1393.9 \mathrm{~s}$, $1363.1 \mathrm{~m}, 1282.5 \mathrm{~m}, 1179.2 \mathrm{w}, 1146.2 \mathrm{w}, 1117.6 \mathrm{w}, 1035.7 \mathrm{~m}, 930.1 \mathrm{w}, 816.3 \mathrm{~m}$, $759.9 \mathrm{~m}, 716.1 \mathrm{~m}, 684.3 \mathrm{~m}, 583.9 \mathrm{w}$ and $543.3 \mathrm{~m}$. 
$\left[\mathrm{Co}_{3}\left(\mathrm{NC}_{5} \mathrm{H}_{3}\left(\mathrm{CO}_{2}\right)_{2}-2,5\right)_{2}\left(\mu_{3}-\mathrm{OH}\right)_{2}\left(\mathrm{OH}_{2}\right)_{2}\right]$ Simulated versus Observed XRPD

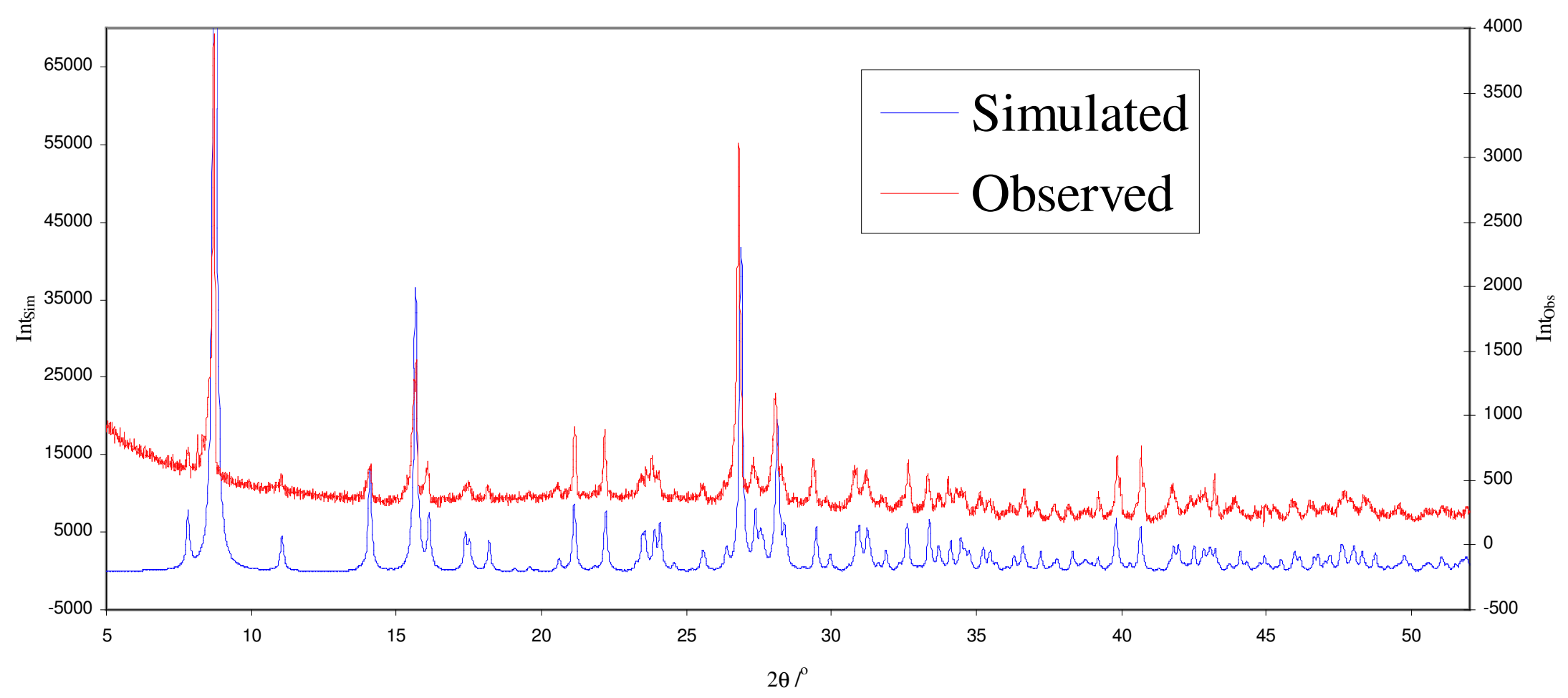

